\section{EARLY ANCESTORS USED TOOTHPICKS}

Researchers have discovered that tooth wear and tooth picking are responsible for dentoalveolar remodelling in 1.77 million-year-old hominin samples from Dmanisi, explaining the wide range of mandibular shape variation. ${ }^{1}$ Variation in cranial and dentoalveolar morphologies in early Pleistocene hominins is well known, but the reasons behind such diversity have been largely unexplored until now.

Increasing severity of tooth wear corresponded with increasing age, with moderate overall wear being recorded in the young adult Dmanisi, wear-induced pathological changes in the older adult and edentulousness in the senile individual. Due to continuous eruption, mesial drift and lingual tipping, tooth wear can have a pronounced effect on mandibular morphology and wear-related reshaping of the jawbones. Such mandibular shape variation is within the normal range of expected variation for a paleopopulation with light to heavy dental wear.
Significantly, horizontal scratches on teeth and local marginal periodontitis add to the growing evidence for habitual use of toothpicks during the period. The findings provide the earliest evidence of tooth-pick induced local periodontitis. The authors conclude that further research into age- and wear-related dentognathic changes is needed to assess the impact on remodelling patterns and variation in other fossil hominins.

1. Margvelashvili A, Zollikofer C P, Lordkipanidze D, Peltomäki T, Ponce de León M S. Tooth wear and dentoalveolar remodeling are key factors of morphological variation in the Dmanisi mandibles. Proc Natl Acad Sci USA 2013; 110: 17278-17283.

\section{By Laura Pacey}

\section{PASHLEY TAKES PODIUM AT FIRST PAN-LONDON LECTURE}

The first pan-London dental lecture on 2 September 2013 was a rare opportunity to hear the worldrenowned academic, Professor David H. Pashley, Emeritus Regents Professor of Oral Biology at the College of Dental Medicine and Professor of Physiology and Endocrinology in the School of Medicine, Georgia Regents University, Augusta, USA.

Professor Pashley spoke on Dentine sensitivity vs. hypersensitivity: treatment options. The lecture was co-chaired by Dr S. K Sidhu of Queen Mary University of London and Professor T. F. Watson of King's College London Dental Institute.

The presentation centred on the possible mechanisms that trigger the pain associated with dentine sensitivity and how sensitivity can turn into hypersensitivity.

The lecture highlights the joint efforts and collaboration between two leading academic institutions as well as industry to bring high profile, international key opinion leaders in the world of dentistry to dental students, academic and clinical staff in London. checks, housing advice, training and further education opportunities.

The dental service relies on qualified volunteers to provide a range of routine dental treatments including check-ups, scale and polishes and fillings.

Each shift is from 10 am to $7 \mathrm{pm}$ and Crisis asks that each volunteer signs up for a minimum of two shifts between 23-29 December.

Online volunteer applications are now open at www.crisis.org.uk/pages/volunteering-at-crisischristmas.html or you can call 03006361000.

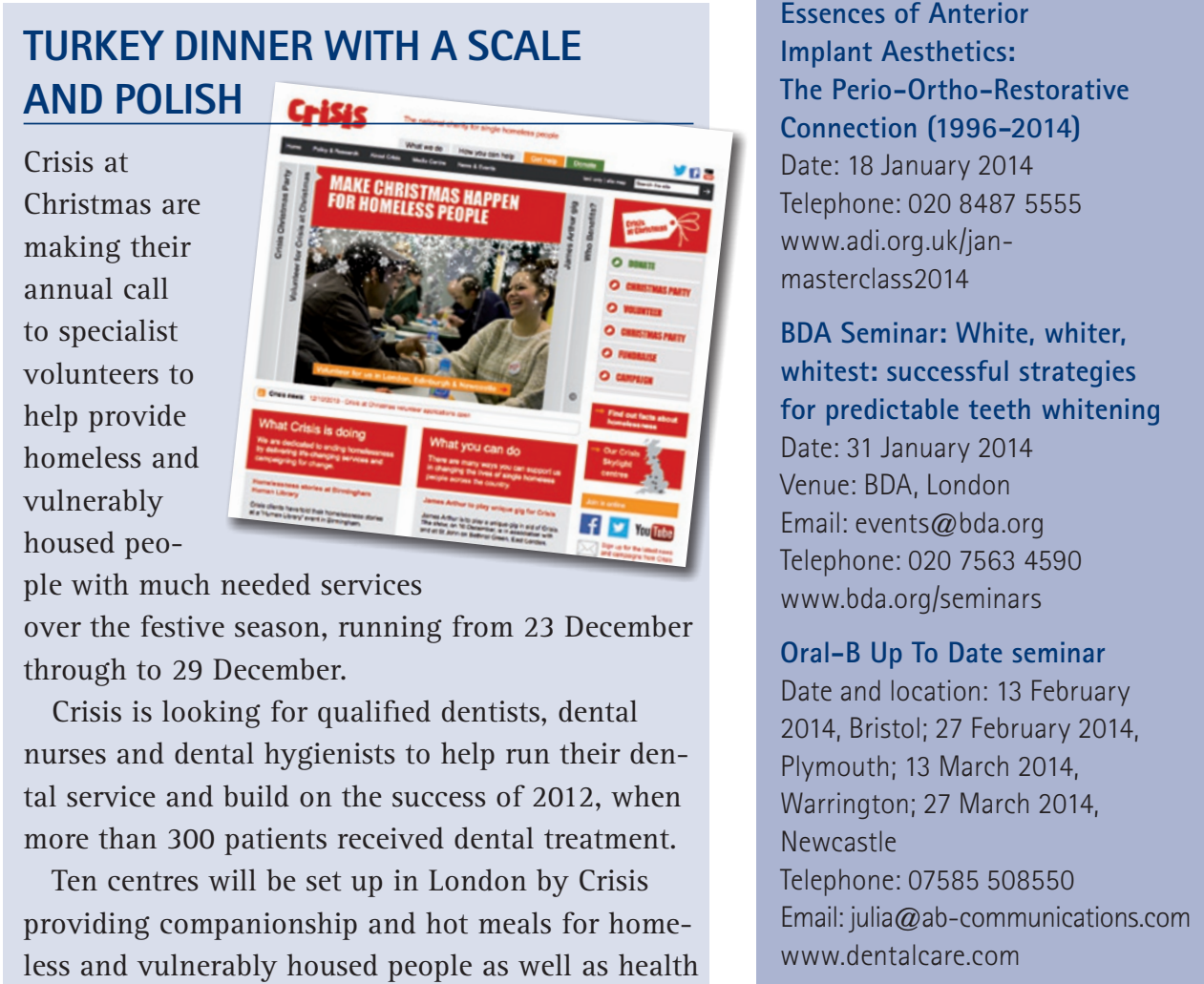

\section{DIARY}

The Dental Operating Microscope in Endodontics

Date: 7 December 2013

Venue: UCL Eastman Dental Institute

Email:marjorie.kelly@ucl.ac.uk Telephone: 02079501234

BDA/BDJ Winter Lecture:

Biofilms: a new approach to dental plaque

Date: 12 December 2013

Venue: BDA, London

www.bda.org/winterlecture

ESAO Conference:

How to practise aesthetic orthodontics safely,

ethically and legally as a GDP

Date: 14 December 2013

Venue: RCOG, London

http://esao.co.uk/event-registration/

Essences of Anterior

Implant Aesthetics:

Date: 18 January 2014

Telephone: 02084875555

www.adi.org.uk/jan -

masterclass2014

BDA Seminar: White, whiter, whitest: successful strategies for predictable teeth whitening

January 2014

Email: events@bda.org

elephone: 02075634590

org/seminars

Date and location: 13 February

2014, Bristol; 27 February 2014

Plymouth; 13 March 2014,

Warrington; 27 March 2014

Telephone: 07585508550

www.dentalcare.com

\section{STUDY CLUB LAUNCH}

The specialist practice PerioLondon celebrated the launch of its study clubs for dentists and hygienists on 18 September at Chandos House, London. Eighty dental professionals attended the celebration hosted by Dr Paul Baker, Professor Ian Needleman and Dr Rajiv Patel. 